\title{
Stability studies of different AC collection network topologies in wind farms connected to weak grids
}

\author{
K Givaki*, D Chen $*$ O Anaya-Lara* \\ * Department of Electronic and Electrical Engineering, University of Strathclyde, Glasgow, United Kingdom \\ k.givaki@strath.ac.uk \\ ${ }^{*}$ Affiliation, Country and contact details, ${ }^{\dagger}$ Affiliation, Country and contact details
}

Keywords: AC collection network, stability, vector current control, weak grid, and wind farm.

\begin{abstract}
In this paper, the stability studies for different wind farm collection network topologies have been performed. As the wind farm becomes larger, the inter-array network becomes larger.so that the impedance of the overall system will be increased. This means that the inter-array configuration can impact the stability of system. The dynamic studies results presented in this paper show that the star collection network topology has the ability to be connected to weaker grid followed by radial, double sided and single side ring collection network topology.
\end{abstract}

\section{Introduction}

Wind energy is the main renewable resource in the United Kingdom with over $13 \mathrm{GW}$ of installed capacity by the end of 2015[1]. The main topology for the modern variable speed wind turbines is the fully rated converter (FRC) turbines that use voltage source converters (VSC) for connecting to the power network. These VSCs are controlled by the vector current control method that controls the decoupled direct and quadrature currents.

Most of the newly constructed wind farms are located offshore or in the rural areas which have higher wind speed but less visual impacts[2] though the grid strength in those areas is not high. The grid strength is measured with the short circuit ratio (SCR) that is the ratio of short circuit capacity MVA to the rated power [3]. By definition if $\mathrm{SCR}>3$ the grid connection is strong, $2<\mathrm{SCR}<3$ the grid is weak and if $\mathrm{SCR}<2$ the grid is very weak [3]. In recent years the average size of wind farms are increased for example in the period of 2010-2015 the average size of wind farms in the EU was more than doubled [4] so many issues should be considered in collection of the power and integration to the main grid.

Different studies looked into collector options for wind farm [5-12]. Power losses, economic considerations, and the reliability issues of different methods have been studied in [6]. The dynamic performance and power loss comparison a comparison for two different collection networks (VSC and Diode bridge based) have been performed in [8]. Furthermore, DC collection methods for wind farms have been studied in
[10]. Power loss studies and The DFIG based wind farm transient stability was studied in [12] and it claims that there will not a transient instability occurs due to the clusters if there is enough reactive power to support the system during faults. Connection of wind turbines and voltage source converter to weak grids has been studied in literature [13-17] but the impacts of different collector topologies on the system stability has not been considered.

In this paper the stability study method that has been proposed in [16] will be used to study different collector topologies impacts on the stability if the wind farm is connected to a weak grid.

The rest of the paper is organized as follow. Different collection network topologies will be discussed in section 2 . Section 3 presents dynamic model of a cluster and wind farm will be developed. The key finding of the dynamic studies will presented at section 4 and finally section 5 concludes the paper.

\section{Wind farm collection system}

To design the collector system for a wind farm different issues must be considered different e.g. size of wind farm, desired reliability level and power losses in the wind farm[6].

It is very important to have a high level reliability in the offshore application as the repair downtime in the offshore environment is higher than that in onshore[10]. So the reliability is improved by adding redundancy to the power flow paths. Collection grids in windfarms has the same architecture as the distribution system[10] so the collection network can be can be either AC or DC [7]. Different AC cluster configurations can be divided into three different groups $[6,7]$ : 1. Star

The Schematic diagram of star connection of wind turbines in a wind farm is shown in Fig.1.a. In this configuration as the cables are required to transfer power of only one turbine, the rated power of cables are reduced. Furthermore if a failure happens in a turbine, it will not affect the other turbines therefore this configuration has very high reliability[6].

2. String or radial

The radial topology is the simplest topology for connecting wind turbines to the grid. The schematic diagram of the string topology is shown in Fig.1.b. As it can be seen in Fig.1.b, there is no additional path in the system so if a fault happens in the system, it will cause that downstream turbines lose the connection to the grid[6]. 


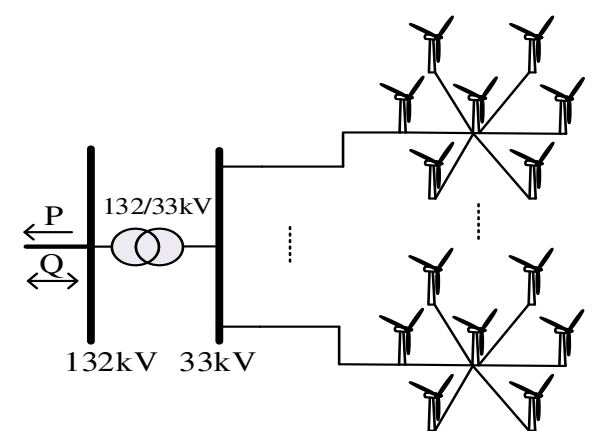

(a)

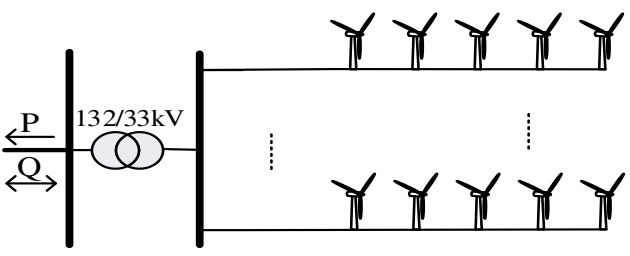

(b)

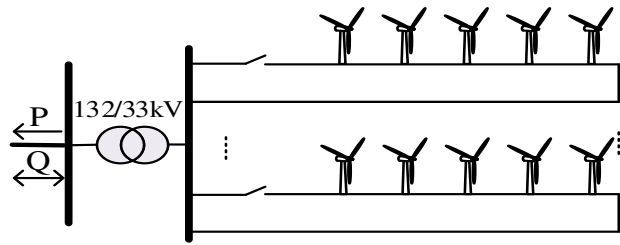

(c)

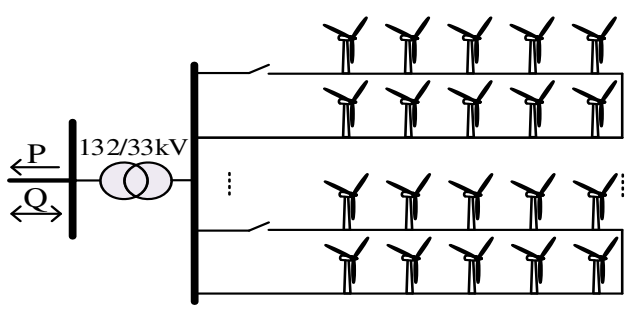

(d)

Fig. 1. Wind farm collection network topologies

\section{Ringed}

Different ring topologies are used to connect offshore wind farms to the main grid. Fig.1.c and Fig.1.d are shown the schematic diagram of the single sided ring collector and double sided ring collector, respectively. In the single sided topology the reliability is improved by adding an additional path for power flow. On the other hand, in the double sided ring topology, the additional power flow path is added by connecting the last turbine in a string to the last turbine of the neighbouring string[6].

Furthermore, DC collection topologies have been proposed in literatures [7-10, 18] which use different type of converters e.g. VSC or Diode rectifiers using different collection network e.g radial, Daisy chain, etc.

\section{Dynamic model}

In this section firstly a single converter is modelled with a Multiple Input-Multiple Output (MIMO) system; therefore the model is extended to another MIMO system to study the dynamic behaviour of wind farm consisting of multiple clusters.

\subsection{Single cluster}

As has been mentioned, voltage source converters are used to connected wind turbines to grid. Furthermore vector current control is used to control the inverter. A state space based method was introduced in [16] to study the stability of grid connected VSCs. The simplified schematic diagram of the converter connected to grid is shown in Fig. 2.

The circuit that is shown in Fig. 2 is modelled to a state space system as (1).

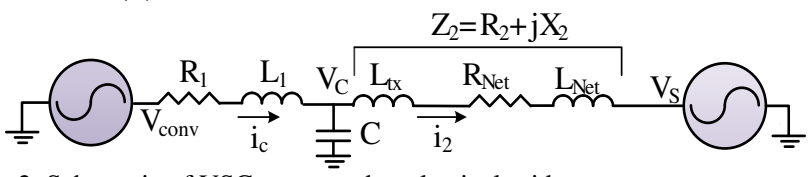

Fig.2. Schematic of VSC connected to electical grid.

$$
\begin{gathered}
\frac{d}{d t}\left[\begin{array}{l}
i_{c_{d}} \\
i_{c_{q}} \\
V_{C_{d}} \\
V_{C_{q}} \\
i_{2_{d}} \\
i_{2_{q}}
\end{array}\right]=\omega_{b} *\left[\begin{array}{cccccc}
-\frac{R_{1}}{L_{1}} & \omega & -\frac{1}{L_{1}} & 0 & 0 & 0 \\
-\omega & -\frac{R_{1}}{L_{1}} & 0 & -\frac{1}{L_{1}} & 0 & 0 \\
\frac{1}{C} & 0 & 0 & -\omega & -\frac{1}{C} & 0 \\
0 & \frac{1}{C} & \omega & 0 & 0 & -\frac{1}{C} \\
0 & 0 & \frac{1}{L_{2}} & 0 & -\frac{R_{2}}{L_{2}} & \omega \\
0 & 0 & 0 & \frac{1}{L_{2}} & -\omega & -\frac{R_{2}}{L_{2}}
\end{array}\right]\left[\begin{array}{l}
i_{c_{d}} \\
i_{c_{q}} \\
V_{C_{d}} \\
V_{C_{q}} \\
i_{2_{d}} \\
i_{2_{q}}
\end{array}\right]+ \\
\omega_{b}\left[\begin{array}{cccc}
0 & 0 & \frac{1}{L_{1}} & 0 \\
0 & 0 & 0 & \frac{1}{L_{1}} \\
0 & 0 & 0 & 0 \\
0 & 0 & 0 & 0 \\
-\frac{1}{L_{2}} & 0 & 0 & 0 \\
0 & -\frac{1}{L_{2}} & 0 & 0
\end{array}\right]\left[\begin{array}{l}
V_{S_{d}} \\
V_{S_{q}} \\
V_{\text {conv }_{d}} \\
V_{\text {conv }_{q}}
\end{array}\right]
\end{gathered}
$$

The complete dynamic system model is shown in Fig. 3.

The dynamic model in Fig 3 includes the vector current control, PLL dynamics, switching delay and the grid connection (Fig.2)[16].

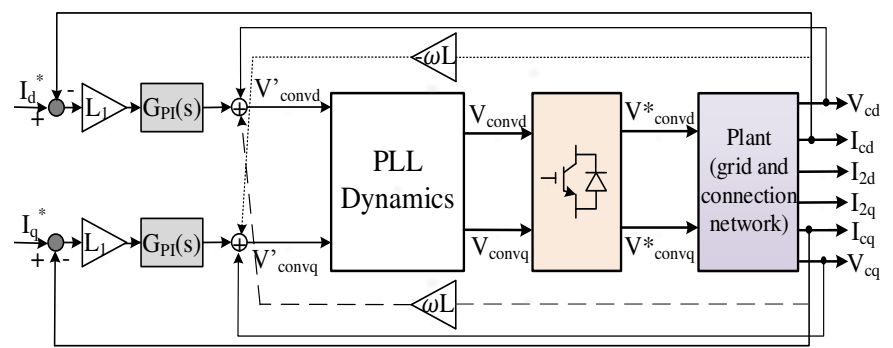

Fig. 3. Block diagram of dynamics of grid connected converter (cluster).

To model a cluster in a wind farm including any number of turbines, the lumped model of the turbines in each cluster can be constructed by using the modelling process that has been discussed in this section. This modelling strategy is the same for any type of the collection network topology. The only 
difference that needs to be considered for different topologies is the change of parameters in (1) depending on inter-cluster cable parameters.

\subsection{Wind farm model}

In this section dynamic model of whole wind farm is developed. Fig. 4 shows the schematic single line circuit of a wind farm connected to a grid through a transformer and transmission line (T model). The state space equivalent of the AC grid connection in Fig.4 is presented in [16]. It is assumed that the grid voltage is aligned to d-axis of the synchronous reference frame therefore $V_{s d}=1$ and $V_{s q}=0$ so that any arbitrary number of clusters can be added to the model[16]. Thus for modelling the windfarm, each cluster can be considered as a standalone MIMO system connected to the AC grid connection state space representative.

The schematic block diagram of dynamics of an aggregated wind farm model is shown in Fig.5. As can be seen in Fig.5, each cluster is modelled by using the MIMO system that was developed in section 3.1. Therefore the stability any number of clusters with any topology and size in a wind farm can be studied as long as the output current of all the clusters are available[16].

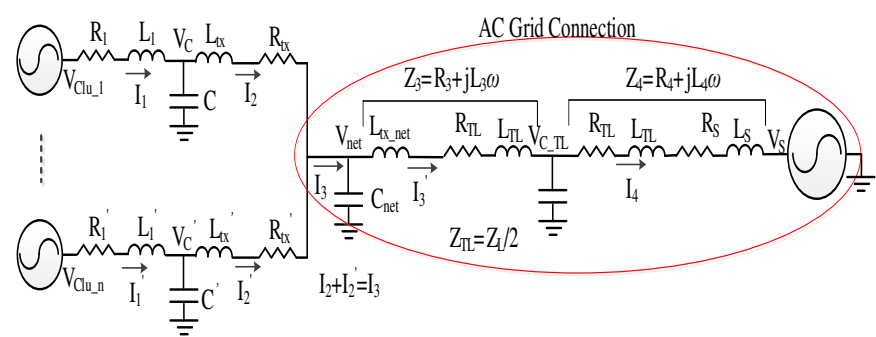

Fig. 4. Single line diagram of two parallel converters with $\mathrm{T}$ line model

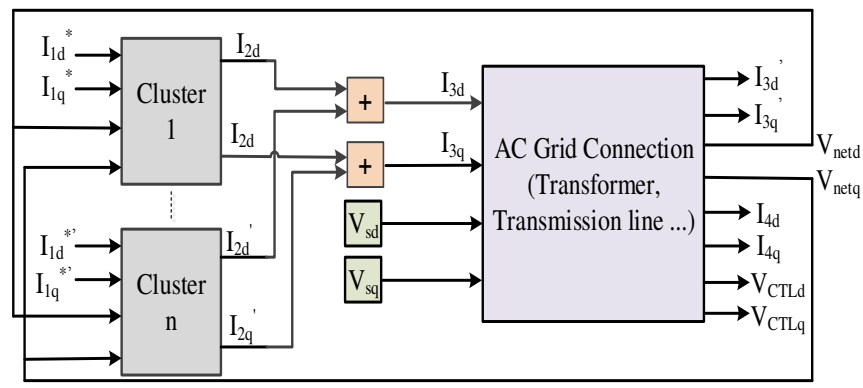

Fig. 5. Block diagram of dynamic model of wind farm.

\section{Simulation results and case studies}

In this section stability of various wind farm collection network topologies including radial, single and double sided ring, and star connections have been studied using the model that has been developed in section 3.in all studies it is assumed that wind farm consists of 40 wind turbine that are divided into 4 clusters. Each turbine is rated at $6 \mathrm{MW}$ and the distance between turbines is assumed to be $1 \mathrm{~km}$. in all the results presented, $\mathrm{X} / \mathrm{R}=4$. All the results presented in this section are from the transfer function from the reference $d$-axis current $\left(i_{d}^{*}\right)$ to the d-axis current $\left(i_{d}\right)$ of one cluster.

The poles map of a system using radial collection network shown in Fig.6. The direction of arrows in Fig. 6 shows poles direction when the SCR value reduces from 100 to 1 . As it is seen in Fig. 6 the system becomes unstable if the SCR reduces beyond 1.67 .

Fig. 7 shows the root loci of the d-axis current transfer function of the single sided ring collection network topology for different grid strengths. As seen in Fig.7. the cluster becomes unstable when the SCR reduces to a value less than 2.04. For this collection topology it is assumed that the power flows through the bypass link so that the inter-cluster cable length is higher.

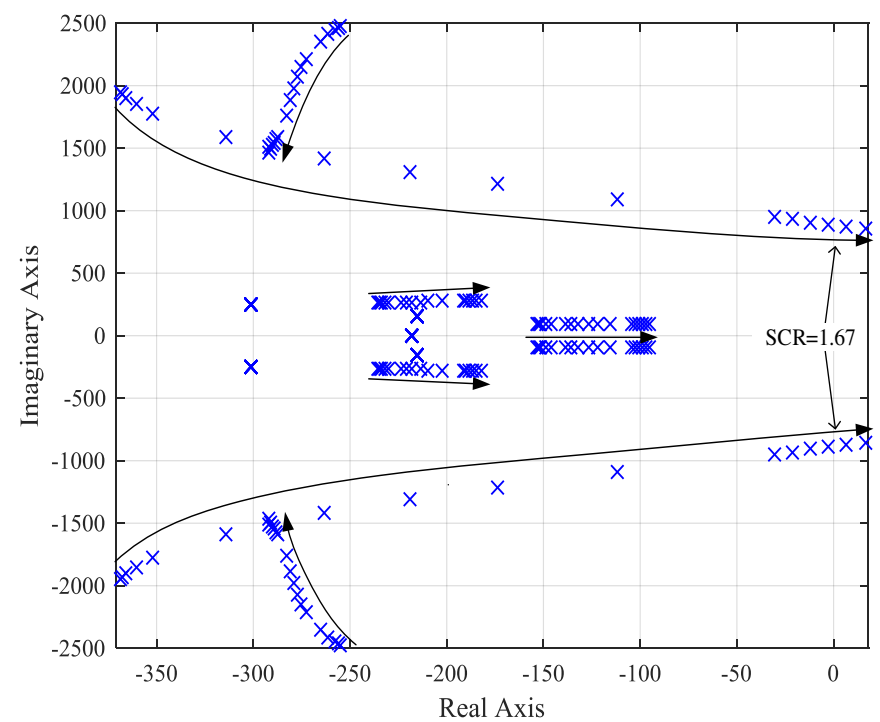

Fig. 6. Poles map of the d-axis current transfer function for radial collection network

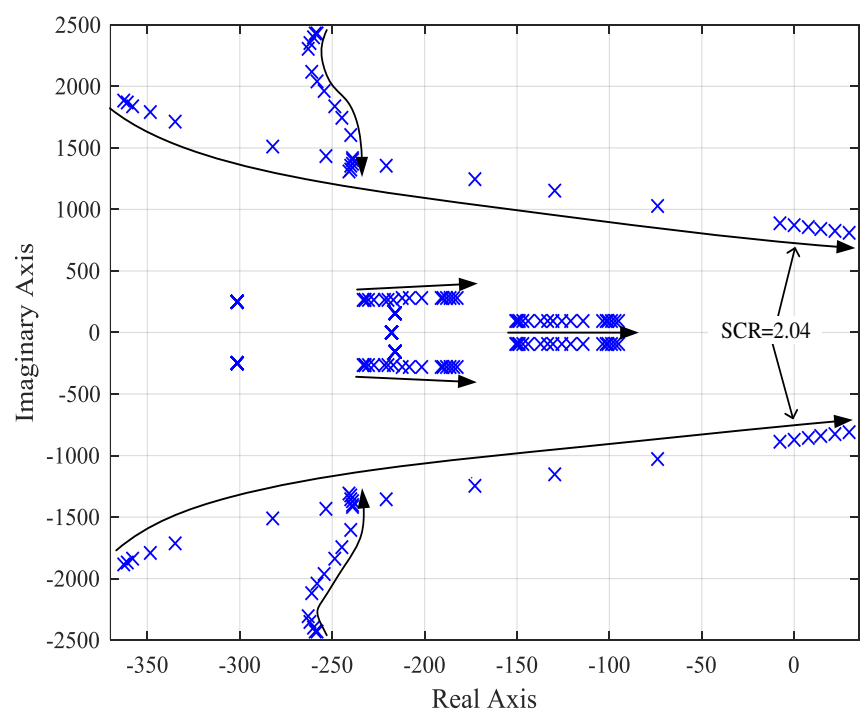

Fig.7 Poles map of the d-axis current transfer function for single sided ring collection network 
Furthermore, the poles map of the d-axis current transfer function of the double sided ring collection network is shown in Fig. 8. As it is seen in Fig.8, the system becomes unstable if the SCR reduces more than 1.72 .

In the double sided ring topology as the cables in a cluster should be able to transfer the rated power of two clusters so the rated power of cables need to be upgraded which it changes the parameter of cables.

Fig. 9 shows the root loci of the d-axis current transfer function of the star collection network. This poles map shows that using the star topology becomes unstable in lowest SCR compared to the other topologies ( $\mathrm{SCR}=1.64)$. As in star topology wind turbines are connected separately to the main connection point in the cluster so that the cable rated power is so much lower than the other topologies.

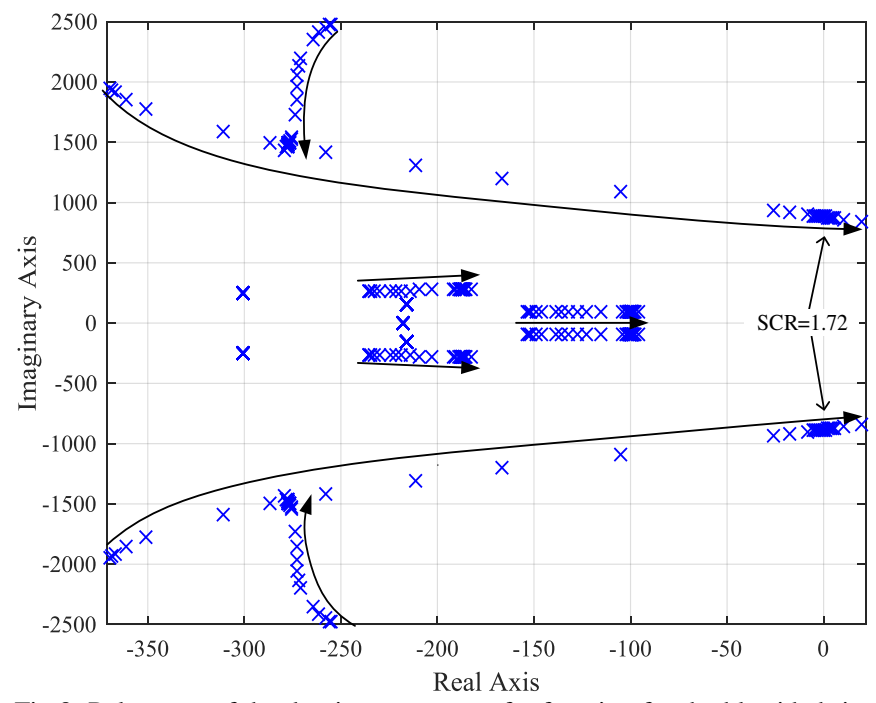

Fig. 8. Poles map of the d-axis current transfer function for double sided ring collection network

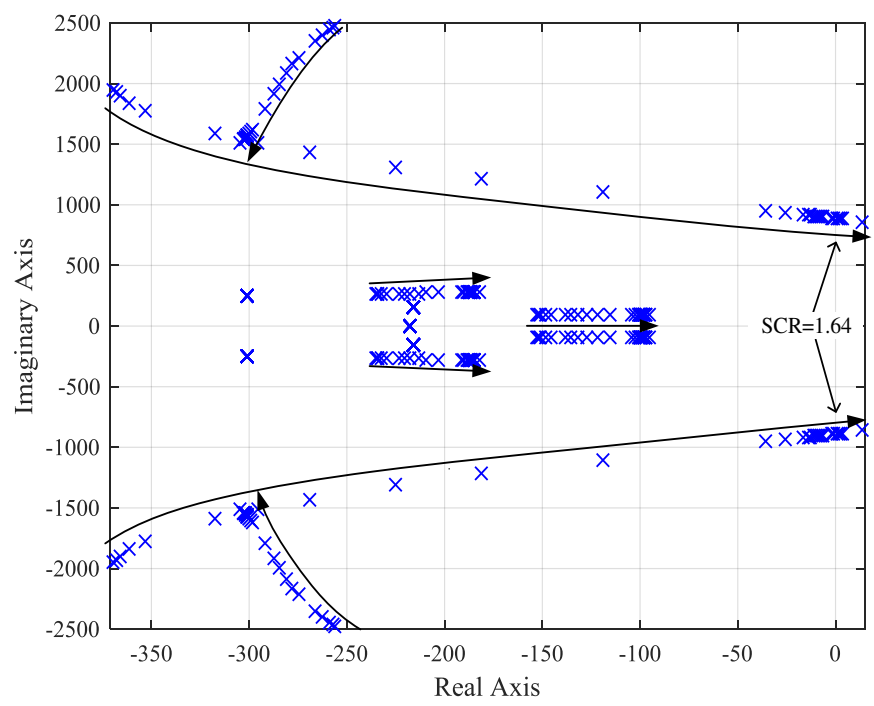

Fig.9. Poles map of the d-axis current transfer function for star collection network.
Fig. 10 shows the open loop bode plot of the d-axis current transfer function for different wind farm collection network topologies for $\mathrm{SCR}=2$. As Fig. 10 shows, star topology has the highest stability margins followed by radial topology and double sided ring topology and single sided ring topology becomes unstable. This totally confirms the results that are obtained by the root locus plots.

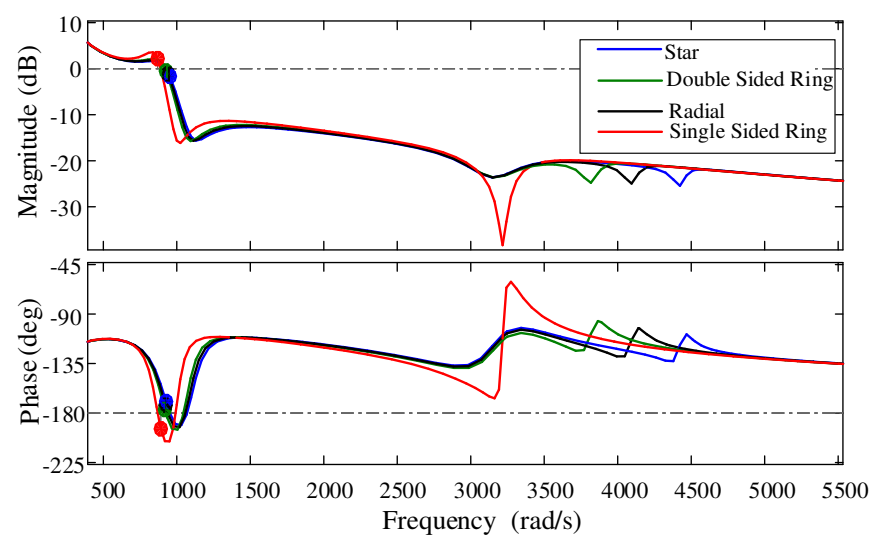

Fig.10. Open loop bode plot of the d-axis current transfer function for different wind farm collection network topologies for $\mathrm{SCR}=2$.

The presented results show that the collection network topology can affect the stability of the system. This happens due to various amount of cables that is used in different topologies and also difference between the cable parameters for different power capacity. It can be concluded that it is very important to study the inter-cluster cables impacts on the network stability as the size of wind farm are getting larger therefore the amount of inter-array/cluster cables increases accordingly.

\section{Conclusion}

As the wind farms become larger the amount of cabled are used in inter-array network is increased. In this paper different collection network was considered and the stability of a wind farm clusters were studied using a MIMO system that allows the study of multiple converters. The analysis showed that star collection network offers the most stable connection to grid if the grid strength reduces.

\section{Acknowledgements}

This work is supported in part by the EPSRC, project reference numbers EP/G037728/1S.

\section{References}

[1] "Wind in power 2015 European statistics," European Wind Energy Association 20162016.

[2] K. Givaki, M. Parker, and P. Jamieson, "Estimation of the power electronic converter lifetime in fully rated converter wind turbine for onshore and offshore wind farms," in 7th IET International Conference on Power Electronics, Machines and Drives 2014, pp. 1-6. 
[3] "IEEE Guide for Planning DC Links Terminating at AC Locations Having Low Short-Circuit Capacities," IEEE Std 1204-1997, pp. 1-216, 1997.

[4] "The European offshore wind industry -key trends and statistics 2015," European Wind Energy Association2016 2016.

[5] C. E. J. D. Elliott, S. J. Finney, "A comparison of technologies for the clustering of multiple wind turbines," in European Wind Energy Association Annual Conference, Vienna, 2013.

[6] G. Quinonez-Varela, G. W. Ault, O. Anaya-Lara, and J. R. McDonald, "Electrical collector system options for large offshore wind farms," IET Renewable Power Generation, vol. 1, pp. 107-114, 2007.

[7] H. J. Bahirat, B. A. Mork, and H. H. K, "Comparison of wind farm topologies for offshore applications," in IEEE Power Engineering Society General Meeting, 2012, pp. 1-8.

[8] K. Musasa, M. N. Gitau, and R. C. Bansal, "Comparative analyses of DC collection grid based power converter topologies for offshore wind farm," in International Conference on Renewable Power Generation 2015, pp. 1-6.

[9] Y. Zhou, D. E. Macpherson, W. Blewitt, and D. Jovcic, "Comparison of DC-DC converter topologies for offshore wind-farm application," in 6th IET International Conference on Power Electronics, Machines and Drives 2012, pp. 1-6.

[10] D. W. Elliott, S. J. Finney, and C. Booth, "Single converter interface for a cluster of offshore wind turbines," in IET Conference on Renewable Power Generation 2011, pp. 1-6.

[11] S. Dutta and T. J. Overbye, "A clustering based wind farm collector system cable layout design," in IEEE
Power and Energy Conference at Illinois, 2011, pp. 16.

[12] B. Xiaoyan, L. Guangyue, and K. C. Wong, "Impact of wind farm cluster with DFIG on Power System transient stability," in IEEE PES Innovative Smart Grid Technologies, 2012, pp. 1-3.

[13] M. Ashabani and Y. A. R. I. Mohamed, "Integrating VSCs to Weak Grids by Nonlinear Power Damping Controller With Self-Synchronization Capability," IEEE Trans. Power Syst, vol. 29, pp. 805-814, 2014.

[14] L. Zhang, L. Harnefors, and H. P. Nee, "Interconnection of Two Very Weak AC Systems by VSC-HVDC Links Using Power-Synchronization Control," IEEE Trans. Power Syst, vol. 26, pp. 344$355,2011$.

[15] A. Egea-Alvarez, S. Fekriasl, F. Hassan, and O. GomisBellmunt, "Advanced Vector Control for Voltage Source Converters Connected to Weak Grids," IEEE Trans. Power Syst., vol. 30, pp. 3072-3081, 2015.

[16] K. Givaki and L. Xu, "Stability analysis of large wind farms connected to weak AC networks incorporating PLL dynamics," in International Conference on Renewable Power Generation 2015, pp. 1-6.

[17] N. P. W. Strachan and D. Jovcic, "Stability of a Variable-Speed Permanent Magnet Wind Generator With Weak AC Grids," IEEE Trans. Power Del, vol. 25, pp. 2779-2788, 2010.

[18] Y. Zhou, D. E. Macpherson, W. Blewitt, and D. Jovcic, "Comparison of DC-DC converter topologies for offshore wind-farm application," in 6th IET International Conference on Power Electronics, Machines and Drives, 2012, pp. 1-6. 